\title{
Середньострокові результати лікування пацієнтів 3 атеросклеротичним ураженням коронарних судин за методикою гібридної реваскуляризації міокарда
}

\author{
Габрієлян А. В., Доманський Т. М., Береговой О. В. \\ Відділ трансплантації серця та кардіохірургії, Національний інститут хірургії та трансплантології \\ ім. О. О. Шалімова НАМН України, м. Київ, Україна
}

\begin{abstract}
Резюме. Пацієнтам із багатосудинним ураженням коронарних артерій показана реваскуляризація міокарда. Не завжди можливо однією з традиційних методик черезшкірного коронарного втручання (РСI) або коронарного шунтування (CABG) виконати повну реваскуляризацію.

Мета. Проаналізувати середньострокові результати лікування в пацієнтів із багатосудинним ураженням коронарного русла шляхом поєднання різних методик PCI та CABG.

Матеріали і методи. Проаналізовано результати лікування 26 пацієнтів, яким виконували реваскуляризацію міокарда шляхом поєднання двох методик: PCI та CABG. Термін спостереження становив $25 \pm 9,6$ місяця.

Результати та обговорення. Отримані дані анкетування, холтерівського моніторингу. Проаналізовані результати ехокардіографії. Середньострокові результати спостереження показали $100 \%$ рівень виживаності, рецидивуючої ішемії міокарда - 1 (3,8 \%) випадок, повторної реваскуляризації - $1(3,8 \%)$ випадок, неврологічні події не відзначено.
\end{abstract}

Висновки. Отримані середньострокові результати свідчать про ефективність і безпечність такого підходу.

Ключові слова: реваскуляризація міокарда, гібридна методика, коронарне шунтування.

Вступ. У пацієнтів із багатосудинним ураженням коронарних артерій (КА) часто відзначають стабільну чи нестабільну стенокардію [1]. Зазвичай таким пацієнтам показана реваскуляризація міокарда з використанням традиційних методик черезшкірного коронарного втручання (PCI) або коронарного шунтування (CABG). Проте не завжди є можливим виконати повну реваскуляризацію однією з методик. Це зумовлено низкою причин, таких як анатомо-топографічна особливість судин міокарда чи їх діаметр та характер ураження атеросклеротичними бляшками.

Проведений метааналіз рандомізованих 28 досліджень Zimarino M. та співавторами [2] мав на меті перевірити, чи стратегія повної реваскуляризації міокарда (ПРМ) порівняно з неповною реваскуляризацією міокарда (НРM), як із черезшкірними коронарними втручаннями, так і з коронарним артеріальним шунтуванням, забезпечує клінічну перевагу в пацієнтів із багатосудинним захворюванням коронарних артерій (MVCAD). Результати дослідження 83695 пацієнтів свідчать, що у групі пацієнтів, яким виконано ПРМ за методикою PCI та CABG, рівень смертності нижчий, ніж у пацієнтів, яким виконано НРМ. Так само ризик інфаркту міокарда (IM) та повторної реваскуляризації нижче в пацієнтів з ПРМ проти НРМ [2].
В одноцентровому проспективному груповому дослідженні послідовних пацієнтів із багатосудинним ураженням коронарних артерій, яким проводили стентування коронарних артерій стентами з лікарським покриттям (drug-eluting stent - DES), із січня 2003 по грудень 2013 року Chang М. та співавтори [3] порівнювали результати з пацієнтами, яким було виконано ПРМ проти НРМ. Дослідники не виявили суттєвої різниці в смертності від усіх причин, а також у відсотку інсульту та потреби в повторній реваскуляризації. У той час як ризик гострого IM під час спостереження був вищим у тих пацієнтів, яким виконували НРМ проти ПРМ.

Питання про те, чи потрібно виконувати повну реваскуляризацію міокарда усіма можливими методами чи можна обмежитися «достатньою» реваскуляризацією, ще обговорюється $[1,4]$.

Мета. Проаналізувати середньострокові результати лікування та оцінити ефективність і безпечність повної реваскуляризації міокарда в пацієнтів з ішемічною хворобою серця та багатосудинним ураженням коронарного русла шляхом поєднання різних методик PCI та CABG на працюючому серці (off-pump).

Матеріали і методи. Проведено аналіз результатів лікування 26 пацієнтів після гібридної коронарної реваскуляризації (ГКР) з ішемічною хворобою серця та 
багатосудинним ураженням КА. Термін спостереження становив $25 \pm 9,6$ місяця. До групи спостереження ввійшло 14 жінок, 12 чоловіків. Середній вік становив $61 \pm 9,6$ року. Цукровий діабет 2-го типу відзначено у $30,8 \%$ (80) пацієнтів. Фракція викиду (ФВ) - $40 \pm 4,1$. Пацієнти до операції мали 1, 2 та 3 інфаркти в анамнезі, що становило $50 \%$ (13), 34,6 \% (9) та 15,4\% (4) відповідно. Нестабільна стенокардія діагностована у 26,9 \% (7), стабільна стенокардія I-II та III-IV класу - у 26,9 \% (7) та 73,1 \% (19) пацієнтів. Усі пацієнти прооперовані без використання апарата штучного кровобігу. У групі 5 пацієнтам, які мали ураження двох коронарних артерій, одна з яких LAD, операцію виконували за мініінвазивною методикою - MIDCAB. Характер ураження коронарних судин у групі мав таке розподілення: у 19 пацієнтів уражені 2 КА, у 6 - 3 КА та в 1 пацієнта - 4 KA.

Результати та обговорення. Опрацьовані результати з 2014 по 2018 рік, у групі ГКР - 26 (100\%) осіб. Середній період спостереження становив 25,0 1 9,6 місяця. Отримані дані анкетування, що передбачало використання Сіетлського опитувальника, розробленого Spertus J. та співавторами [5]. Якість життя за кожною з п'яти шкал вимірюється у відсотках, а саме $0 \%$ відповідає найгіршій якості життя, а $100 \%$ - відмінній. Якість життя та стан здоров’я оцінювали за такими показниками:

- обмеження фізичної активності/навантаження Physical Limitation (PL) - 81,9 $\pm 6,25 \%$;

- стабільність (вираженість) нападів стенокардії Angina Stability (AS) - $100 \%$;

- частота нападів стенокардії - Angina Frequency (AF) $-87,5 \pm 25 \%$;

- задоволеність лікуванням - Treatment Satisfaction (TS) $-85,62 \pm 13,3 \%$;

- ставлення пацієнта до хвороби - Disease Perception (DP) $-66,65 \pm 9,64 \%$.

За результатами холтерівського моніторингу аритмогенні ускладнення у вигляді пароксизмів фібриляції передсердь відзначено в 3 пацієнтів (11\%), що потребувало корекції антиаритмічної терапії.

Показниками ЕхоКГ, які аналізувалися, були: ФВ, що досягала в групі 51,12 \pm 6,22 \%, кінцево-діастолічний об'єм (КДО) - 102,8 $\pm 23,04$ см$^{3}$, кінцево-систолічний об'єм (KCO) - 43,16 $\pm 14,45 \mathrm{~cm}^{3}$, кінцево-діастолічний індекс (КДІ) - 48,66 $\pm 21,21 \mathrm{~cm}^{3} / \mathrm{M}^{2}$, кінцевосистолічний індекс (KCI) - 22,62 $\pm 5,9 \mathrm{~cm}^{3} / \mathrm{M}^{2}$.

При середньому періоді спостереження 2 роки фактична виживаність у групі ГКР становила $100 \%$, смертельних випадків не було (таблиця 1). В одного пацієнта $(3,8 \%)$ була зареєстрована рецидивуюча ішемія міокарда, яка потребувала повторної реваскуляризації у вигляді рестентування. Неврологічні події не зафіксовано. В 11,5 \% (3) пацієнтів спостерігалася шлунково-кишкова кровотеча, пов'язана із загостренням хронічної вираз-

\section{Таблиця 1}

Середньострокові результати

\begin{tabular}{lc} 
Показник & HCR $\mathbf{n ~ ( \% ) ~}$ \\
\hline Летальний наслідок, n (\%) & $0(0)$ \\
\hline Інфаркт міокарда, $\mathrm{n}(\%)$ & $1(3,8)$ \\
\hline Неврологічні події, n (\%) & $0(0)$ \\
\hline Повторна реваскуляризація, n (\%) & $1(3,8)$ \\
\hline Шлунково-кишкові кровотечі & 3 \\
\hline Час спостереження, місяці & $25 \pm 9,6$ \\
\hline Усього пацієнтів у групі, n (\%) & $26(100)$
\end{tabular}

кової хвороби шлунка, що вимагала консультації гастроентеролога та проведення відповідної терапії.

\section{Висновки}

Поєднання операції off-pump CABG і PCI дозволяє виконати повну реваскуляризацію міокарда з максимальним ефектом при мінімальному втручанні і є ще одним методом вибору в лікуванні пацієнтів із багатосудинним ураженням. Середньострокові результати показали достатню ефективність і безпеку такого підходу. Показання, терміни, послідовність і техніка виконання процедур вимагають подальшого дослідження. Поєднавши дані різних кардіохірургічних центрів та проведене мультицентрове дослідження, можна обрати кращу стратегію лікування пацієнтів із багатосудинним ураженням коронарних артерій.

\section{Список використаних джерел References}

1. Sandoval Y, Brilakis ES, Canoniero M, Yannopoulos D, Garcia S. Complete versus incomplete coronary revascularization of patients with multivessel coronary artery disease. Curr Treat Options Cardiovasc Med. 2015;17:366. https://doi.org/10.1007/s11936-015-0366-1

2. Zimarino M, Ricci F, Romanello M, Di Nicola M, Corazzini A, De Caterina R. Complete myocardial revascularization confers a larger clinical benefit when performed with state-of-the-art techniques in high-risk patients with multivessel coronary artery disease: A metaanalysis of randomized and observational studies. Catheter Cardiovasc Interv. 2016 Jan 1;87(1):3-12. https:// doi.org/10.1002/ccd.25923

3. Chang M, Ahn JM, Kim N, Lee PH, Roh JH, Yoon SH, et al. Complete versus incomplete revascularization in patients with multivessel coronary artery disease treated with drug-eluting stents. Am Heart J. 2016;179:157-65. https://doi.org/10.1016/j.ahj.2016.06.020

4. Ong AT, Serruys PW. Complete revascularization: coronary artery bypass graft surgery versus percutaneous coronary intervention. Circulation. 2006;114:249-55. https:// doi.org/10.1161/CIRCULATIONAHA.106.614420

5. Spertus JA, Winder JA, Dewhurst TA, Deyo RA, Fihn SD. Monitoring the quality of life in patients with coronary artery disease. Am. J Cardiol. 1994 Dec 15;74(12):1240-4. 


\title{
Mid-term Results of Hybrid Myocardial Revascolarization for the Patients with the Coronary Arteries Disease
}

\author{
Gabrielyan A., Domansky T., Beregovoy O. \\ Shalimov's National Institute of Surgery and Transplantation to National Academy of Medical Sciences of Ukraine, \\ Kyiv, Ukraine
}

Abstract

Introduction. Myocardial revascularization using traditional percutaneous coronary intervention (PCI) or coronary artery bypass grafting $(\mathrm{CABG})$ is indicated to the patients with multivessel coronary artery (CA) damage. However, complete revascularization using a single method may not always be possible. Results of the study enrolling 83,695 patients indicate that in the group of patients who underwent complete myocardial revascularization using the PCI and CABG methods, the mortality rate was lower in those who underwent complete myocardial revascularization.

Objective of the study was to analyze the medium-term treatment outcomes in patients with coronary heart disease and multivessel coronary artery damage who underwent PCI and CABG.

Materials and methods. The treatment outcomes in 26 patients undergoing myocardial revascularization by means of combining two methods - percutaneous coronary intervention (PCI) and off-pump CABG - were analyzed. The observation time was $25.0 \pm 9.6$ months.

Results and discussion. The survey data obtained included the scores of the Seattle Questionnaire developed by Spertus J. et al. [6] and Holter monitoring data. The medium-term results of EchoCG have been analyzed. Medium-term observational results showed $100 \%$ survival rate, $1(3.8 \%)$ case of myocardial ischemia recurrence, 1 (3.8\%) case of re-revascularization; neurological events were not revealed.

Conclusions. The medium-term results obtained indicate the effectiveness and safety of this approach.

Keywords: myocardial revascularization, hybrid technique, coronary bypass.

Стаття надійшла в редакцію 21.03.2019. 